\title{
Influence of the ion-exchange membrane on the performance of double-compartment microbial fuel cells
}

\author{
Y. Asensio, C.M. Fernandez-Marchante, J. Lobato, P. Cañizares, M.A. Rodrigo*
}

Department of Chemical Engineering. Faculty of Chemical Sciences \& Technologies. Universidad de Castilla La Mancha. Campus Universitario s/n 13071 Ciudad Real. Spain.

\begin{abstract}
Four two-compartment microbial fuel cells (MFCs), equipped with the same components except for the membranes, were operated for two months within the same operation conditions, in order to evaluate the effects of the ion exchange membranes (IEM) and the hydraulic retention time (HRT). Results obtained point out that a MFC equipped with Nafion-117 achieves higher current and power densities $\left(829 \mathrm{~mA} \mathrm{~m}^{-2}\right.$ and $268.37 \mathrm{~mW} \mathrm{~m}^{-2}$, respectively) than when the same type of MFC is equipped the cationic exchange membrane Neosepta CMX or the anionic exchange membrane Neosepta AMX, despite both membranes have higher ion exchange capacities. However, no significant differences were found in the wastewater treatment capacities of the different MFCs. In addition, hydraulic retention time (HRT) was found to play an important role in the output energy generation, because low values contributes to minimize the biofouling and, hence, to produce higher current densities.
\end{abstract}

\section{Keywords}

Membranes; microbial fuel cell; nafion; neosepta; hydraulic retention time

*Author to whom all correspondence should be addressed: manuel.rodrigo@uclm.es 


\section{Highlights}

- MFC equipped with Nafion 117 performs better than with Neosepta CMX

- MFC technology is robust generating an electric current even when anionic membrane Neosepta AMX was used

- The type of membrane does not affect the wastewater treatment capacity of MFCs

- Lower HRT leads to higher electrical performance because they minimize biofouling 


\section{Introduction}

Nowadays, the consumption of fossil fuels is causing an increase in the carbon dioxide pollution levels, which is believed to be a major cause of global warming [1-3]. Attending this problem, the search of alternative sources of energy is increasing day by day [4]. One of the most interesting technologies are Microbial Fuel Cells (MFCs), which are bioelectrochemical reactors that produce an electric current using microorganisms populations as biocatalysts $[5,6]$ and that allows to use wastewater as a fuel, then helping to avoid the use of fossil fuels.

Typically, a MFC consists of two compartments, an anode compartment that host microorganism cultures, which oxidize the organic matter contained in a fuel, producing $\mathrm{CO}_{2}$, protons and electrons, and a cathode compartment, where an electron acceptor, oxygen in most cases is reduced to water [7]. Electrons pass through an external electric circuit, whereas protons pass throughout an ionic exchange membrane (IEM) to the cathode compartment. MFC performance depends on several factors, due to the complex biological reactions occurring inside the device, being two of them the IEM implemented in the MFC and the hydraulic retention time (HRT) at which this MFC is operated [8-14]. Several authors have studied the influence of different commercial types of IEM [15-18], because no specific membranes have been developed up to now for MFCs. In the literature, Nafion 117 (DuPont, USA) is the most commonly used proton exchange membrane (PEM) for MFCs, due to its good mechanical durability, the proper chemical resistance to PEMC and MFC environment and high cation conductivity [19] which allows to obtain high output voltages $[16,20]$. However, several important drawbacks have been detected during their application, such as the occurrence of substrate and oxygen crossover [21], which cause the reduction of MFC performance in long-term operation tests, and the increase of the ohmic internal resistance due to undesired 
biofouling processes, associated to the use of IEM in MFC [22, 23]. To try to overcome these problems, other cation exchange membranes (CEM) and anion exchange membranes (AEM) have been studied for MFCs, although in lesser extension. With regard to CEM, their lower price in comparison to Nafion membranes is a clear advantage [9, 24, 25], despite their use exhibits the same problems associated to Nafion [16]. Regarding AEM, Kim et al. [9] discovered that the use of AEM could facilitate proton transfer by using phosphate or carbonate buffers, leading to high output voltages. Nevertheless, AEMs are more liable to deformation, which may rise significantly the internal resistance of MFC, so initially they could not be advisable for long-term operations.

Long-term operation in MFCs inevitably leads to membrane biofouling, in which microorganisms and organic substrates forms a thicker layer on the membrane surface avoiding the pass of protons through the IEM, limiting the oxygen reduction reaction in the cathode compartment and, in turn, increasing importantly the ohmic resistance of the system $[26,27]$. Several authors have reported this undesirable phenomenon in doublechamber MFC and when it happens IEMs should be replaced with a new one. This encourages studies to delay the biofouling process and hence to increase the entire lifetime of the system. In some of these studies [12, 28, 29], it has been suggested that HRT could play an important role in the membrane biofouling delay, although further work was recommended.

With this background, the aim of this research was to evaluate the effect of three different materials (Nafion 117, Neosepta CMX and Neosepta AMX) as IEM in the output power generation of double chamber MFCs. In addition, two different HRT were studied using Nafion 117 to observe the effect of this parameter on the biofouling formation. 


\section{Materials and methods}

\subsection{Microbial fuel cell set-up}

The set-up used in this work consisted of MFCs with two chambers $\left(4 \mathrm{~cm}^{3}\right.$ volume each one) separated by three different membranes. An anionic one, Neosepta AMX, and two cationic membranes, Neosepta CMX and Nafion 117. Neosepta AMX and CMX membranes were provided by ASTOM Corporation (Japon) and were selected because of the higher ion exchange capacity as compared to Nafion 117 (DuPont, USA), which according to the literature[30] are almost the double, so better performance is expected. To avoid the clogging problems acrylic tubes with an inner diameter of $40 \mathrm{~mm}$ and length $180 \mathrm{~mm}$ were used. Each MFC is formed by two HPL (high pressure laminate) plates and two silicon plates to improve the mechanical properties and avoid liquid losses. Carbon felt (Sigracell@GFA6EA) was used as anodic and cathodic electrode material $\left(7.06 \mathrm{~cm}^{2}\right.$ surface area each), due to the high porosity and its good properties (good electric conductivity, chemical stability and low cost). In order to decrease the internal resistances (related to ohmic losses) of the MFC, the electrode spacing between the anode and the cathode was minimized. An external resistance of $120 \Omega$ was connected to the electrodes. Dissolved oxygen in the cathodic chamber was supplied by a fishery compressor that can provide a maximum flow rate of $1.6 \mathrm{~L} \mathrm{~min}^{-1}$ to avoid the limitation of oxygen in the cathodic chamber.

\subsection{Inoculum and wastewater}

The inoculum used in the anode compartment was obtained from the activated sludge reactor at the municipal Wastewater Treatment Plant of Ciudad Real (Spain) and concentrated by sedimentation. Activated sludge was introduced into the anodic compartment with raw wastewater in a 1:2 ratio during three days; after this period MFCs 
were fed with synthetic wastewater. The fresh media had an initial COD of $5000 \mathrm{mg} \mathrm{L}^{-1}$ and it was composed by $8.05 \mathrm{~g} \mathrm{~L}^{-1}$ sodium acetate, $2.77 \mathrm{~g} \mathrm{~L}^{-1} \mathrm{NaHCO}_{3}, 1.85 \mathrm{~g} \mathrm{~L}^{-1}$ $\left(\mathrm{NH}_{4}\right)_{2} \mathrm{SO}_{4}, 1.11 \mathrm{~g} \mathrm{~L}^{-1} \mathrm{KH}_{2} \mathrm{PO}_{4}, 0.92 \mathrm{~g} \mathrm{~L}^{-1} \mathrm{MgCl}_{2}, 1.25 \mathrm{~g} \mathrm{~L}^{-1} \mathrm{CaCl}_{2}$, and $0.07 \mathrm{~g} \mathrm{~L}^{-1}$ $\left(\mathrm{NH}_{4}\right) \mathrm{Fe}\left(\mathrm{SO}_{4}\right)_{2}$. To obtain comparable results, all MFCs were started-up at the same time and room temperature $\left(25 \pm 2{ }^{\circ} \mathrm{C}\right)$. Two different hydraulic retention times (HRT), $3.16 \mathrm{~d}$ and $6.32 \mathrm{~d}$, were tested in MFC equipped with the Nafion 117 membrane. HRT was defined as the ratio between $\mathrm{V}_{\mathrm{c}}(\mathrm{mL})$, which is the volume of the anodic compartment in MFC, and $\mathrm{Q}_{\mathrm{f}}\left(\mathrm{mL} \mathrm{d}^{-1}\right)$, which is the feed flow in the anodic compartment.

\subsection{Characterization techniques}

A digital multimeter (Keithley 2000 multimeter) was connected to the system to monitor continuously the value of the cell voltage at the value of the external load $(120 \Omega)$.

The $\mathrm{pH}$, conductivity and dissolved oxygen were measured using a GLP22 Crison ${ }^{\circledR} \mathrm{pH}-$ meter, a GLP 31 Crison ${ }^{\circledR}$ conductivity meter and an Oxi538 WTW® oxy-meter, respectively. Total suspended solids (TSS) were measured gravimetrically according to standard methods. Chemical oxygen demand (COD) was determined using a Velp ECO16 digester and a Pharo 100 Merck spectrophotometer analyzer. Polarization curves have been carried out in MFC by varying the resistance in the circuit and measuring the voltage. Three important parameters were evaluated: the open circuit voltage (OCV) or the maximum allowable MFC voltage, the maximum intensity and the maximum power density of the MFC. In addition, the shape of curves gives important information about the limiting processes, which control the performance of the cell. Power density $\left(\mathrm{mW} \mathrm{m}^{-}\right.$ $\left.{ }^{2}\right)$ and current density $\left(\mathrm{mA} \mathrm{m}^{-2}\right)$ were calculated based on the surface area of the anode $\left(7.06 \mathrm{~cm}^{-2}\right)$. 


\section{Results and Discussion}

Fig.1. compares the produced current density and the wastewater treatment capacity (measured as COD consumption rate) when operational steady-state values were reached, after two-month of continuous operation of four double-compartment MFCs equipped with three types of membranes, two cation exchange membrane and one anionic membrane. As seen, membrane does not behave as a simple separator of compartments but it also has a high influence on output power. In addition, two test were carried out with the Nafion-117 by operating the cell at two HRT conditions ( $3.16 \mathrm{~d}$ and $6.32 \mathrm{~d})$, in order to observe the influence of this key parameter in the electric behavior and the wastewater treatment capacity of MFCs.
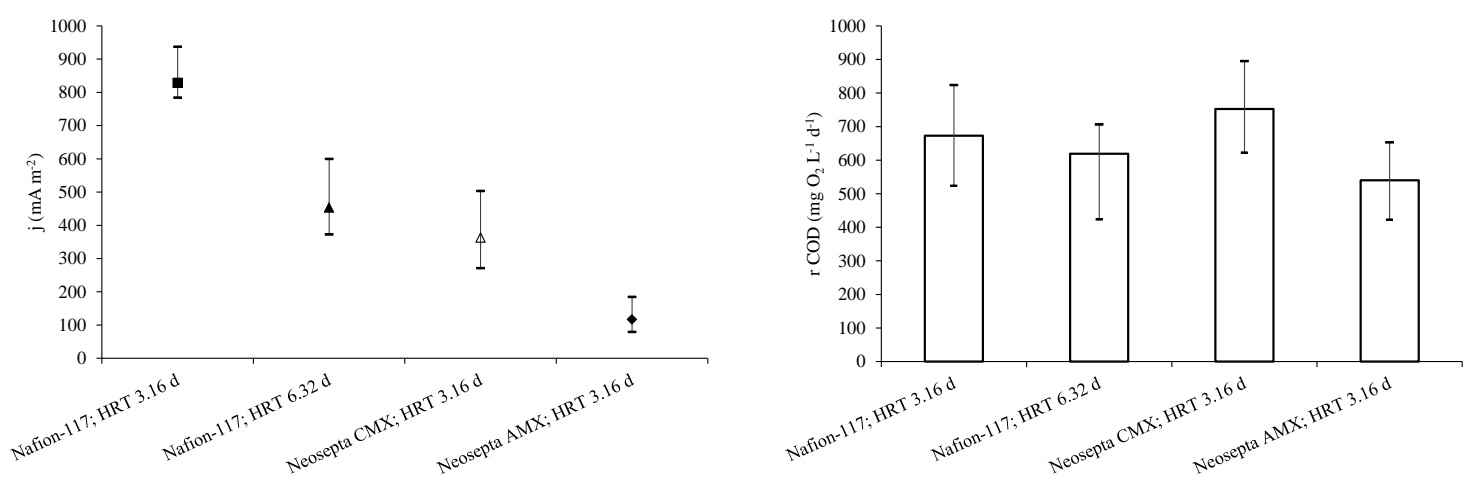

Figure 1. Current densities and COD consumption rates and deviations obtained in the steady state in MFC under two different HRT and different membranes. Operational conditions: $[\mathrm{COD}]_{0}=5000 \mathrm{mg} \mathrm{O}_{2} \mathrm{dm}^{-3}$, Carbon felt as electrode material. (匹) HRT=3.16 $\mathrm{d}$ and Nafion-117 membrane, $(\boldsymbol{\Delta}) \mathrm{HRT}=6.32 \mathrm{~d}$ and Nafion-117 membrane, $(\Delta)$ Neosepta CMX membrane and HRT $=3.16 \mathrm{~d},(\diamond)$ Neosepta AMX membrane and HRT $=3.16 \mathrm{~d}$. 
In comparing the electricity produced by the cells that underwent the same HRT, it can be seen that, when the systems were stabilized, the AEM performs worse than CEMs . Thus, after two months of operation, MFC with Neosepta AMX reached a stationary current density of $117 \mathrm{~mA} \mathrm{~m}^{-2}$, much lower than the current density reached by the MFCs equipped with both CEMs which, in addition, showed great discrepancies between them. The MFC equipped with the Neosepta CMX reached $363 \mathrm{~mA} \mathrm{~m}^{-2}$ (3.1 times higher than the cell equipped with the AEM) and the MFC equipped with the Nafion-117 produced $829 \mathrm{~mA} \mathrm{~m}^{-2}$ (7.1 times higher than the cell equipped with the AEM and 2.3 times higher than the cell equipped with the other CEM). As the three cells were fed with the same substrate and undergo exactly the same operating conditions, this behavior has to be explained attending to the way in which the oxygen reduction reaction (ORR) is affected by the different proton exchange capacity of the three membranes. The higher proton exchange capacity of the CEMs allows higher concentration of protons in the cathode compartment, whereas AEM were unable to transfer protons through the membrane limiting the proton concentration in the cathode compartment, increasing the internal resistance of the bio-electrochemical device and decreasing the output current density. Regarding the comparison of the conventional Nafion-117 and the two Neosepta membranes, it is important to point out that initially, these results were not expected because the ion exchange capacity (IEC) of Neosepta CMX is within the range 1.5-1.8 meq. $\mathrm{g}^{-1}$ and that of the Neosepta AMX is within the range $1.4-1.7$ meq. $\mathrm{g}^{-1}$, which are almost double than the IEC of Nafion 117 (which is only of 0.9 meq. $\mathrm{g}^{-1}$ )[30]. This clearly points out that IEC is not the most relevant parameter for the selection of the IEM of a MFC.

On the other hand, Fig 1 also informs about the strong influence of HRT on energy generation, and it points out that lower HRT helps the MFC to reach a higher current 
density. This observation will be discussed afterwards but, initially, it can be related to the lower concentration of microorganisms contained in the electrolyte, which contributes to decrease the fouling of the membranes.

Fig. 1.b informs that despite of the very high influence of the type of membrane on the energy generation, there is not a significant link between the selected IEM and the wastewater treatment capacity of the different MFCs. This behavior could be explained by taking into account that the biological process is limited by the anode compartment, where electroactive and non-electroactive bacteria are expected to consume COD. MFC with higher HRT showed a significantly higher decrease of COD consumption rate as compared to the MFC with lower HRT, because of the less active population expected to be produced under these conditions.

Values of $\mathrm{pH}$ in the anode and cathode compartments and the anode conductivity at the steady state are shown in Fig. 2, where it can be observed that these values do not depend significantly on the type of the membrane used in the MFC. There is a very important dispersion, which points out the complexity of the bioprocess happening in both MFC compartments. The only remarkable observation is the lower value reached in the cathode chamber and the higher value in the anode chamber when the anionic membrane is used in the MFC, as compared to the results exhibited by the cells equipped with CEMs. As it is well-described in the literature, $\mathrm{pH}$ is strongly related to oxygen reduction (this process consumes protons) and to organic matter consumption, which typically produced protons. This means that higher achieved values of anolyte $\mathrm{pH}$ and lower achieved values of catholyte $\mathrm{pH}$ can be related to a lower activation (reflected on the lower amount of protons involved) associated to the MFC with anionic membranes, as compared to the other two cationic ones. 

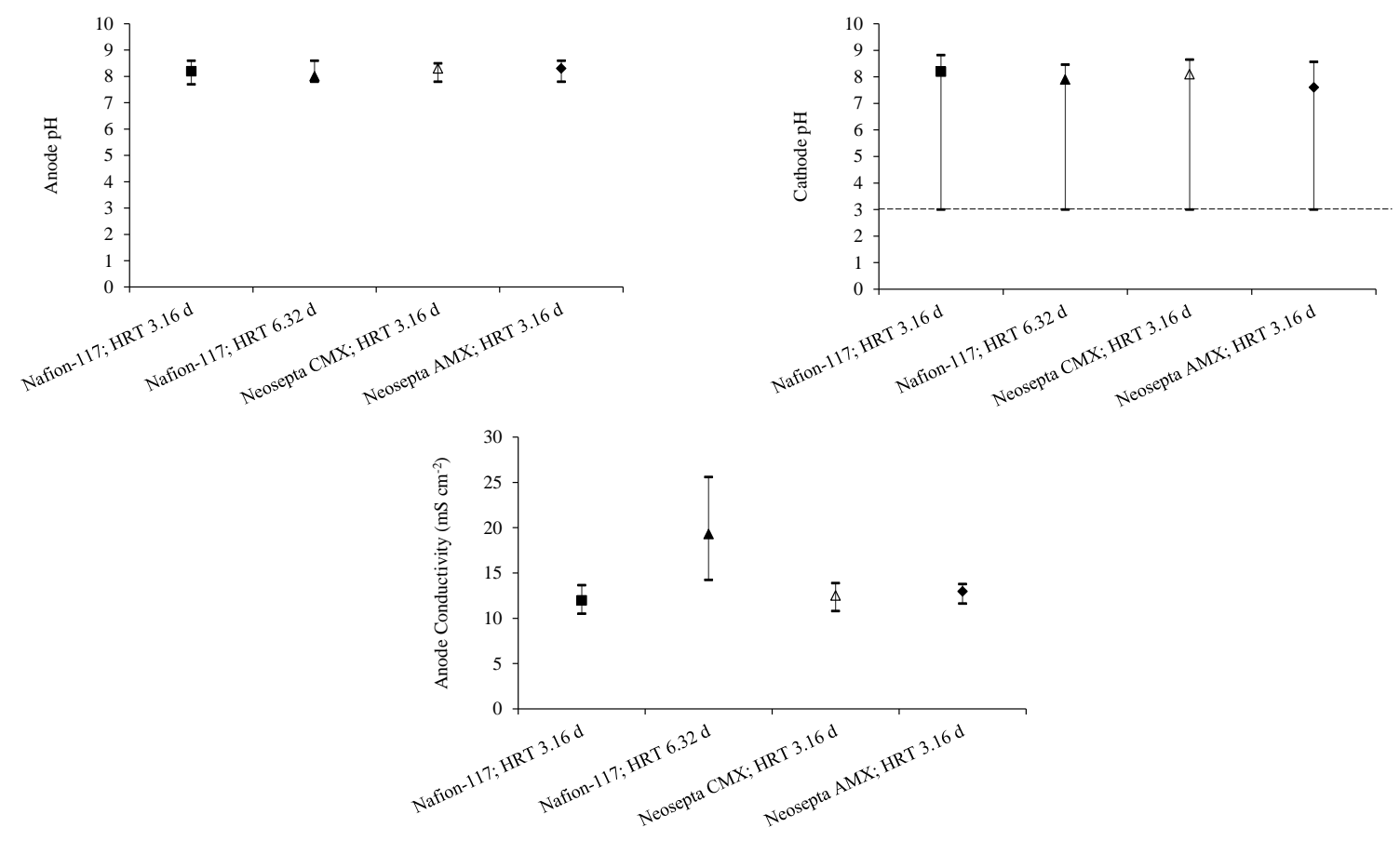

Figure 2. (a) Anodic chamber $\mathrm{pH}$, (b) Cathodic chamber $\mathrm{pH}$ in MFC (c) Anode conductivity. Operational conditions: $[\mathrm{COD}]_{0}=5000 \mathrm{mg} \mathrm{O}_{2} \mathrm{dm}^{-3}$, Carbon felt as electrode material. ( $\square)$ HRT=3.16 d and Nafion-117 membrane, $(\boldsymbol{\Delta}) \mathrm{HRT}=6.32 \mathrm{~d}$ and Nafion-117 membrane, $(\Delta)$ Neosepta CMX membrane and HRT=3.16 d, $(\diamond)$ Neosepta AMX membrane and HRT $=3.16 \mathrm{~d}$.

As for $\mathrm{pH}$, changes in the conductivity are similar for the three cells operated with the same HRT but equipped with different membranes. However, this is not the case of the cell operated with the Nafion membrane at higher HRT, for which a much higher conductivity is observed in the anodic chamber, which could be indicative of a decrease of the ion exchange capacity of the membranes due to be biofouling layer on the membrane surface or to the clogging of the membrane by the species contained in the bulk electrolyte. Anyhow, this decrease of the proton conductivity has to be reflected in an increase of the ohmic resistance of the MFC that, in turn, may lead to the decrease of the electric performance of the whole system. 
Recognizing the importance of the biofouling phenomenon in the electric performance of MFCs in the long-term operation, the microorganism concentration in the anode compartment was evaluated during the whole experiment for each MFC. Fig. 3. shows the changes in the microorganism concentration during the two-month operation in the four cells evaluated.

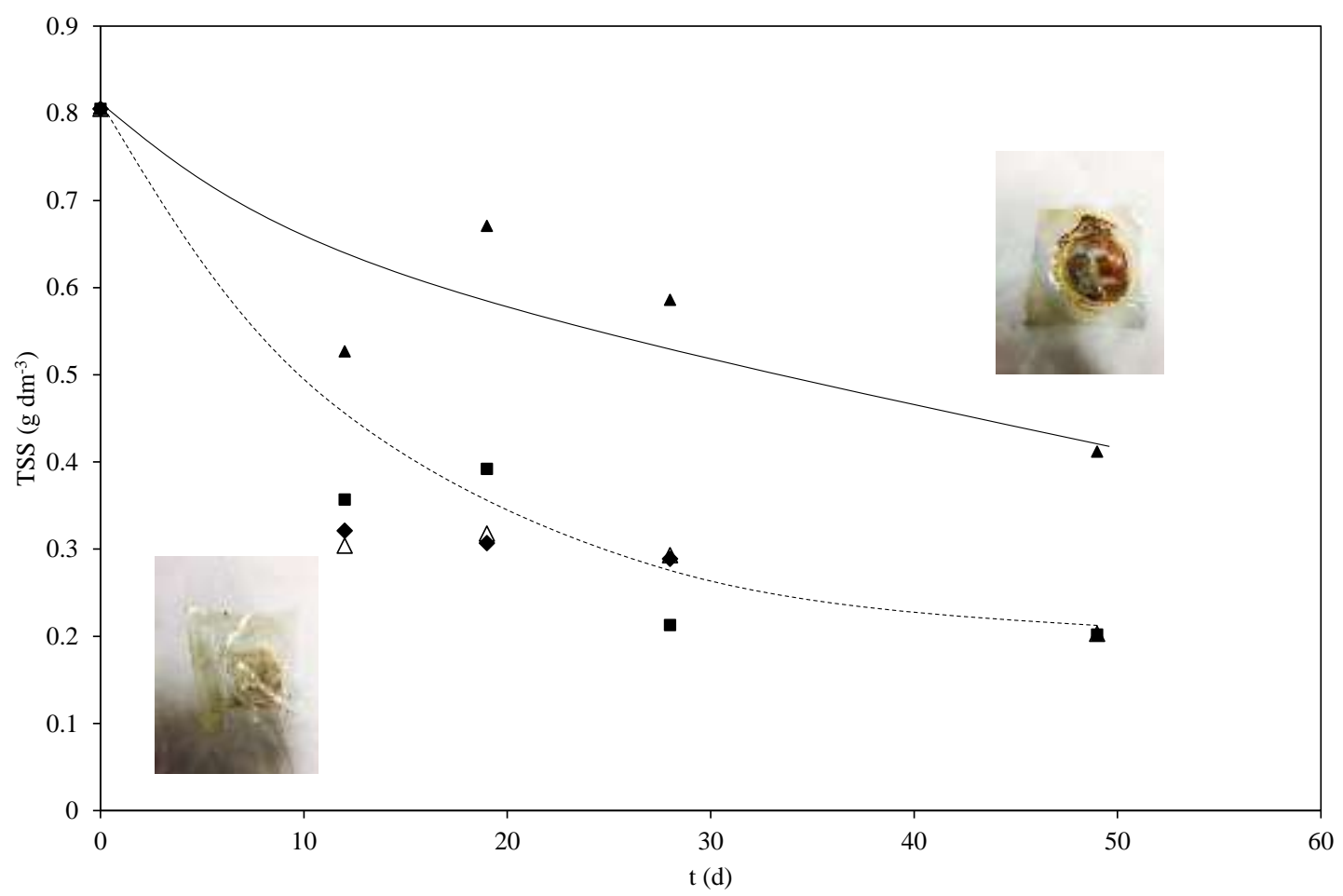

Figure 3. Total suspended solids (TSS) in the anodic chamber in MFC under two different HRT and different membranes. Operational conditions: $[\mathrm{COD}]_{0}=5000 \mathrm{mg} \mathrm{\textrm {O } _ { 2 }}$ $\mathrm{dm}^{-3}$, Carbon felt as electrode material. ( $\left.\boldsymbol{\square}\right) \mathrm{HRT}=3.16 \mathrm{~d}$ and Nafion-117 membrane, $(\boldsymbol{\Delta})$ HRT $=6.32 \mathrm{~d}$ and Nafion-117 membrane, $(\Delta)$ Neosepta CMX membrane and HRT=3.16 $\mathrm{d},(\diamond)$ Neosepta AMX membrane and HRT=3.16 d.

For the same HRT, the use of different types of membranes does not significantly affect the microorganism concentration in the anodic chamber, which, at it can be seen, slightly decrease over time down to a steady-state value in the four tests. On the other hand, major 
changes are found in comparing the effect of the HRT. Higher microorganism concentration were found in the anode compartment at higher HRT, because anolyte solution (in which microorganism and organic fuel are contained) stays longer time in the compartment (two times more), and can lead to a higher biofouling and inorganic fouling of the membrane and hence to a worse performance of the cell. This is reflected in the picture obtained from both Nafion 117 membranes after the tests, in which it can be clearly seen how in the membrane used in the MFC operated at the largest HRT the biofilm is more appreciable.

Polarization curves were carried out during the test and Fig. 4 shows the curves recorded in the last operational days, when the system showed a stable response, MFCs with Neosepta membranes showed a low performance in the bioelectrochemical operation as it be be seen in Fig.4. The different shapes observed in the four MFCs give important information about the behavior of the three membranes in the long-term operation.
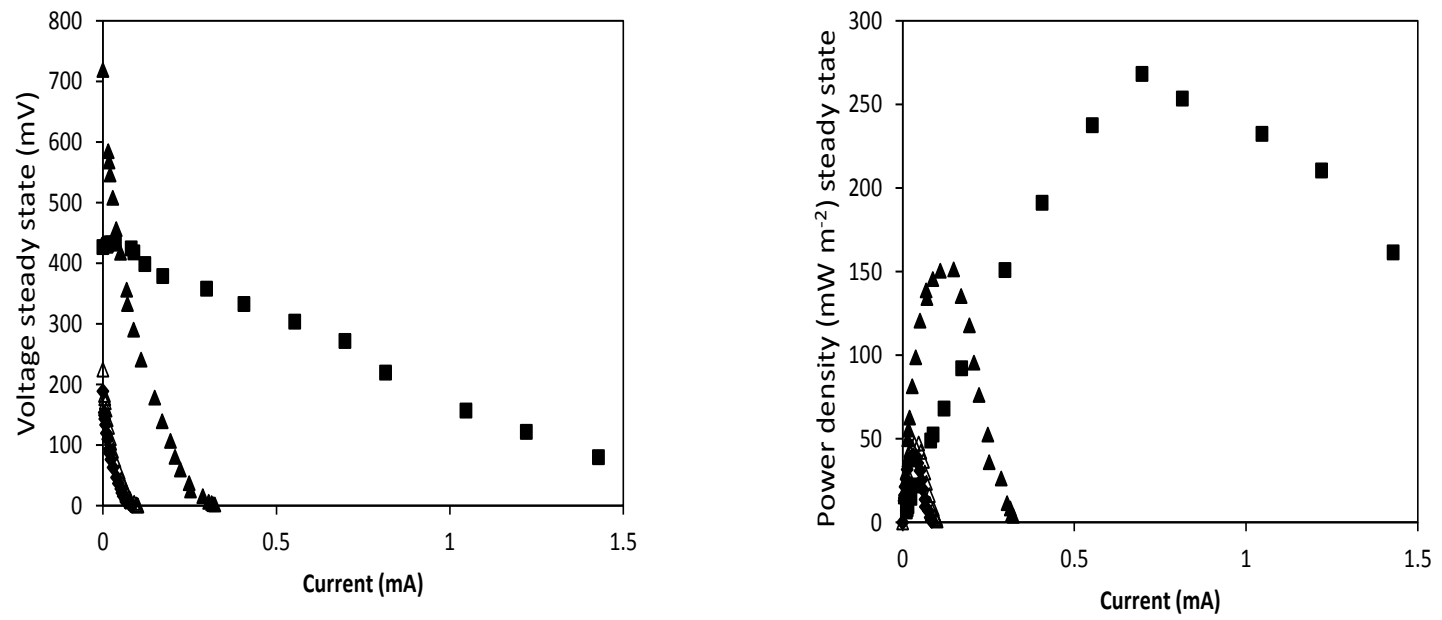

Figure 4. Polarization curves at the steady state. Operational conditions: $[C O D]_{0}=5000$ mg $\mathrm{O}_{2} \mathrm{dm}^{-3}$, Carbon felt as electrode material. (a) HRT=3.16 $\mathrm{d}$ and Nafion-117 membrane, $(\boldsymbol{\Delta}) \mathrm{HRT}=6.32 \mathrm{~d}$ and Nafion-117 membrane, $(\Delta)$ Neosepta CMX membrane and HRT=3.16 d, ( $\bullet)$ Neosepta AMX membrane and HRT=3.16 d. 
It can be observed how the Nafion 117 membrane reached much higher electric performance as compared with Neosepta-CMX and, especially with the Neosepta-AMX. In addition, strong differences arose in comparing the effect of the HRT. The decrease of the slope of the V-I curve allows to envisage the higher ohmic resistance the longer the HRT. As it was pointed out before, this larger resistance can be explained by the more important biofouling of the membranes at larger HRT, despite the higher ionic conductivity observed in the anodic chamber. Further discussion about obtained electric current and power density are discussed in Fig. 5 where the key parameters of these curves are compared.
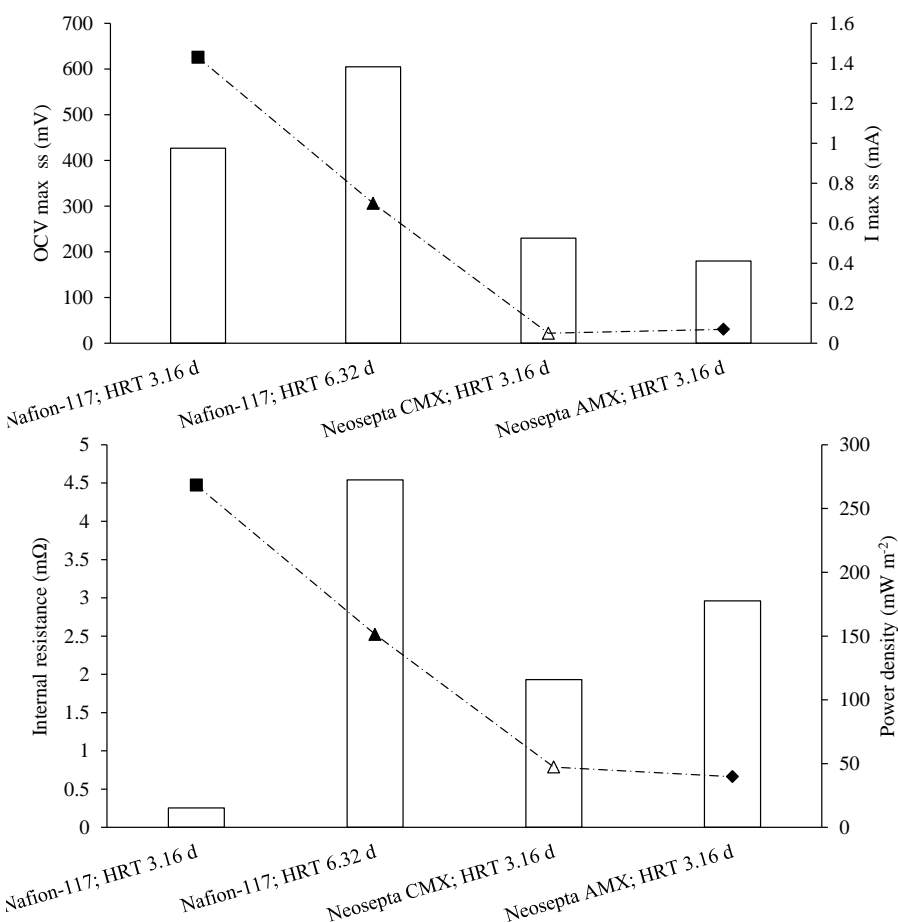

Figure 5. Maximum OCV (bars) and current achieved (points) (Part a) and Maximum Power Density (points) and Internal Resistance (bars) (part b) measure for each MFC tested in this work. Operational conditions: $[\mathrm{COD}]_{0}=5000 \mathrm{mg} \mathrm{O}_{2} \mathrm{dm}^{-3}$, Carbon felt as electrode material. ( $\square$ ) HRT=3.16 d and Nafion-117 membrane, $(\boldsymbol{\Delta}) \mathrm{HRT}=6.32 \mathrm{~d}$ and Nafion-117 membrane, $(\Delta)$ Neosepta CMX membrane and HRT=3.16 d, $(\diamond)$ Neosepta AMX membrane and HRT=3.16 d. 
Maximum electric currents and open circuit voltages (OCV) were achieved by the Nafion-117, which maximized the maximum electric current to $1.43 \mathrm{~mA}$, whereas the electric performance of Neosepta-CMX and Neosepta-AMX, (0.05 and $0.07 \mathrm{~mA}$ respectively) demonstrate that the use of this membranes are not suitable for the production of bioenergy in the long-term operation. The low output electric response of the Neosepta membranes could be related to the lower thickness of the membranes as compared to Nafion-117. Despite of the theoretical decrease of the internal resistance of the MFC with thicker membranes, oxygen and substrate crossover through membranes may be more likely to occur, decreasing the electric efficiency of the MFCs as it has been demonstrated in Fig.5.

HRT plays an important role in the electric performance of MFCs as it can be seen in the same figure. Higher OCV was obtained at higher HRT but more electric current was produced at lower HRT. Thus, the electric current produced with low HRT overcomes by almost $60 \%$ the electric current achieved by the MFC operated with a HRT of $6.32 \mathrm{~d}(0.57$ mA). Electroactive bacteria seems to be more likely to growth with low HRTs, which favor higher available organic matter concentration for microorganism populations according to the results. However, this differences could not be only explained in terms of the different membranes used, because MFC is a multiparametrical technology, which can be influenced by a high number of parameters.

Power density and the theoretical internal resistance of the different MFC can also be obtained from polarization curves. As it can be seen in Fig. 5, the maximum power density was obtained by the MFC equipped with the PEM membrane $\left(268.37 \mathrm{~mW} \mathrm{~m}^{-2}\right)$, almost $70 \%$ over the power density attained by Neosepta-CMX and Neosepta AMX (47.3 mW2 and $39.7 \mathrm{~mW} \mathrm{~m}^{-2}$, respectively). Attending to the fact that polarization curves were 
obtained in the long-term operation, when the system was stabilized, it can be said that Neosepta CMX and Neosepta AMX perform worse than Nafion-117 for bioenergy generation using MFC technology. Theoretical internal resistance calculated by the slope of the polarization curves V-I, have been plot in Fig.5, and relevant information can be obtained. The minimum internal resistance is associated with the use of Nafion-117 membrane, explaining why the use of this membrane maximized the produced output current. At the same time higher internal resistance were obtained by MFC with Neosepta CMX and Neosepta AMX.

When different HRT were studied, important differences between HRTs were observed in power density and internal resistance. It was found that lower HRT improves in a 55\% the attainable value of power density produced when $6.32 \mathrm{~d}$ of HRT was selected (151.37 d). In terms of internal resistance, it can be seen how MFC with Nafion-117 and $6.32 \mathrm{~d}$ of HRT, has the higher internal resistance, even more than using the two different Neosepta membranes. However, higher values of power density were obtained despite of this unexpected result. The high proton exchange selectivity, which avoid the ORR limitation process in the cathode compartment, and the wider thickness of Nafion-117, which limits the oxygen and substrate crossover, increase the internal resistance but the electric performance is better than using the Neosepta membranes.

\section{Conclusions}

- Both anionic and cathionic IEM can be used to separate the electrodic compartments in MFCs. While the wastewater treatment capacity of MFCs is not greatly affected by the cationic or anionic exchange of the membrane, the output energy obtained is strongly affected by them. 
- MFCs with Nafion-117 IEM perform better in terms of output current density, due to the decrease in the associated internal resistance using Nafion-117 respecting Neosepta membranes, increasing the electric performance of this MFC.

- HRT directly affects the electric performance and the wastewater treatment capacity of MFCs. Low HRT improve the output energy generation, while high HRT should be avoid for MFCs operation.

\section{Acknowledgements}

Financial support from the Agencia Estatal de Investigación (AEI) of the Spanish Ministry of Economy and Competitiveness (MINECO) through project CTQ2013-49748EXP (Explora Program) is gratefully acknowledged

\section{References}

[1] N. Gaurav, S. Sivasankari, G.S. Kiran, A. Ninawe, J. Selvin, Utilization of bioresources for sustainable biofuels: A Review, Renewable and Sustainable Energy Reviews 73 (2017) 205-214.

[2] M. Ståhl, J. Berghel, H. Williams, Energy efficiency, greenhouse gas emissions and durability when using additives in the wood fuel pellet chain, Fuel Processing Technology 152 (2016) 350-355.

[3] D. Moreira, J.C.M. Pires, Atmospheric CO2 capture by algae: Negative carbon dioxide emission path, Bioresour. Technol 215 (2016) 371-379.

[4] H. Hiegemann, D. Herzer, E. Nettmann, M. Lübken, P. Schulte, K.G. Schmelz, S. Gredigk-Hoffmann, M. Wichern, An integrated $45 \mathrm{~L}$ pilot microbial fuel cell system at a full-scale wastewater treatment plant, Bioresour. Technol 218 (2016) 115-122.

[5] Y. Asensio, I.B. Montes, C.M. Fernandez-Marchante, J. Lobato, P. Cañizares, M.A. Rodrigo, Selection of cheap electrodes for two-compartment microbial fuel cells, Journal of Electroanalytical Chemistry 785 (2017) 235-240.

[6] B.E. Logan, Simultaneous wastewater treatment and biological electricity generation, Water Science and Technology, 2005, pp. 31-37.

[7] Y. Asensio, C.M. Fernandez-Marchante, J. Lobato, P. Cañizares, M.A. Rodrigo, Influence of the fuel and dosage on the performance of double-compartment microbial fuel cells, Water Research 99 (2016) 16-23.

[8] P. Długołecki, B. Anet, S.J. Metz, K. Nijmeijer, M. Wessling, Transport limitations in ion exchange membranes at low salt concentrations, Journal of Membrane Science 346(1) (2010) 163-171. 
[9] R.K. Jung, S. Cheng, S.E. Oh, B.E. Logan, Power generation using different cation, anion, and ultrafiltration membranes in microbial fuel cells, Environmental Science and Technology 41(3) (2007) 1004-1009.

[10] H.-X. Chang, Q. Fu, Y. Huang, A. Xia, Q. Liao, X. Zhu, Y.-P. Zheng, C.-H. Sun, An annular photobioreactor with ion-exchange-membrane for non-touch microalgae cultivation with wastewater, Bioresour. Technol 219 (2016) 668-676.

[11] D. Akman, K. Cirik, S. Ozdemir, B. Ozkaya, O. Cinar, Bioelectricity generation in continuously-fed microbial fuel cell: Effects of anode electrode material and hydraulic retention time, Bioresour. Technol 149 (2013) 459-464.

[12] X.A. Walter, S. Forbes, J. Greenman, I.A. Ieropoulos, From single MFC to cascade configuration: The relationship between size, hydraulic retention time and power density, Sustainable Energy Technologies and Assessments 14 (2016) 74-79.

[13] J.R. Trapero, L. Horcajada, J.J. Linares, J. Lobato, Is microbial fuel cell technology ready? An economic answer towards industrial commercialization, Applied Energy 185 (2017) 698-707.

[14] Z.A. Stoll, Z. Ma, C.B. Trivedi, J.R. Spear, P. Xu, Sacrificing power for more costeffective treatment: A techno-economic approach for engineering microbial fuel cells, Chemosphere 161 (2016) 10-18.

[15] S.E. Oh, B.E. Logan, Proton exchange membrane and electrode surface areas as factors that affect power generation in microbial fuel cells, Applied Microbiology and Biotechnology 70(2) (2006) 162-169.

[16] A. Sotres, J. Díaz-Marcos, M. Guivernau, J. Illa, A. Magrí, F.X. Prenafeta-Boldú, A. Bonmatí, M. Viñas, Microbial community dynamics in two-chambered microbial fuel cells: Effect of different ion exchange membranes, Journal of Chemical Technology and Biotechnology 90(8) (2015) 1497-1506.

[17] J.X. Leong, W.R.W. Daud, M. Ghasemi, K.B. Liew, M. Ismail, Ion exchange membranes as separators in microbial fuel cells for bioenergy conversion: A comprehensive review, Renewable and Sustainable Energy Reviews 28 (2013) 575-587. [18] O. Lefebvre, Y. Shen, Z. Tan, A. Uzabiaga, I.S. Chang, H.Y. Ng, A comparison of membranes and enrichment strategies for microbial fuel cells, Bioresour. Technol 102(10) (2011) 6291-6294.

[19] B.E. Logan, Microbial Fuel Cells, Wiley2008.

[20] S. Mateo, M. Rodrigo, L.P. Fonseca, P. Cañizares, F.J. Fernandez-Morales, Oxygen availability effect on the performance of air-breathing cathode microbial fuel cell, Biotechnology Progress 31(4) (2015) 900-907.

[21] H. Rismani-Yazdi, S.M. Carver, A.D. Christy, O.H. Tuovinen, Cathodic limitations in microbial fuel cells: An overview, Journal of Power Sources 180(2) (2008) 683-694.

[22] M. Miskan, M. Ismail, M. Ghasemi, J. Md Jahim, D. Nordin, M.H. Abu Bakar, Characterization of membrane biofouling and its effect on the performance of microbial fuel cell, International Journal of Hydrogen Energy 41(1) (2016) 543-552.

[23] D. Li, J. Liu, Y. Qu, H. Wang, Y. Feng, Analysis of the effect of biofouling distribution on electricity output in microbial fuel cells, RSC Advances 6(33) (2016) 27494-27500.

[24] H.V.M. Hamelers, A. Ter Heijne, T.H.J.A. Sleutels, A.W. Jeremiasse, D.P.B.T.B. Strik, C.J.N. Buisman, New applications and performance of bioelectrochemical systems, Applied Microbiology and Biotechnology 85(6) (2010) 1673-1685.

[25] B.R. Dhar, H.S. Lee, Membranes for bioelectrochemical systems: challenges and research advances, Environmental Technology (United Kingdom) 34(13-14) (2013) 1751-1764. 
[26] K.Y. Kim, E. Yang, M.Y. Lee, K.J. Chae, C.M. Kim, I.S. Kim, Polydopamine coating effects on ultrafiltration membrane to enhance power density and mitigate biofouling of ultrafiltration microbial fuel cells (UF-MFCs), Water Research 54 (2014) 62-68.

[27] J. Xu, G.P. Sheng, H.W. Luo, W.W. Li, L.F. Wang, H.Q. Yu, Fouling of proton exchange membrane (PEM) deteriorates the performance of microbial fuel cell, Water Research 46(6) (2012) 1817-1824.

[28] L. Ren, Y. Ahn, B.E. Logan, A Two-Stage Microbial Fuel Cell and Anaerobic Fluidized Bed Membrane Bioreactor (MFC-AFMBR) System for Effective Domestic Wastewater Treatment, Environmental Science \& Technology 48(7) (2014) 4199-4206. [29] J. Wang, Y. Zheng, H. Jia, H. Zhang, Bioelectricity generation in an integrated system combining microbial fuel cell and tubular membrane reactor: Effects of operation parameters performing a microbial fuel cell-based biosensor for tubular membrane bioreactor, Bioresour. Technol 170 (2014) 483-490.

[30] T.W. Xu, Ion exchange membranes: State of their development and perspective, Journal of Membrane Science 263(1-2) (2005) 1-29. 